\title{
Tamanho de parcela e número de repetições em aveia preta
}

\author{
Plot size and number of repetitions in black oat
}

\begin{abstract}
Alberto Cargnelutti Filho ${ }^{\mathrm{I}}$ Bruna Mendonça Alves ${ }^{\mathrm{II}}$ Marcos Toebe ${ }^{\mathrm{II}}$ Cláudia Burin ${ }^{\mathrm{II}}$ Gustavo Oliveira dos Santos" Giovani Facco ${ }^{\text {II }}$ Ismael Mario Márcio Neu ${ }^{\text {III }}$ Réges Bellé Stefanello ${ }^{\text {III }}$
\end{abstract}

\section{RESUMO}

Os objetivos deste trabalho foram determinar o tamanho ótimo de parcela e o número de repetições, para avaliar a massa verde de aveia preta (Avena strigosa Schreb). Foram realizados 18 ensaios de uniformidade de $8 m \times 8 m\left(64 m^{2}\right)$. Cada ensaio foi dividido em 64 unidades experimentais básicas (UEB) de $1 \mathrm{~m} \times 1 \mathrm{~m}$, totalizando 1.152UEB. Foi pesada a massa verde das plantas de cada UEB. Nove ensaios (576UEB) foram avaliados aos 102 dias após a semeadura e os outros nove ensaios (576UEB) aos 106 dias após a semeadura. O tamanho ótimo de parcela (Xo) foi determinado por meio do método da curvatura máxima do modelo do coeficiente de variação e as comparações de médias, entre as épocas de avaliação, foram feitas pelo teste $t$ de Student. $O$ número de repetições, para experimentos nos delineamentos inteiramente casualizado e blocos ao acaso, em cenários formados pelas combinações de i tratamentos $(i=3,4, \ldots$, 50) e d diferenças mínimas entre médias de tratamentos a serem detectadas como significativas a $5 \%$ de probabilidade, pelo teste de Tukey, expressas em percentagem da média do experimento $(d=10 \%, 12 \%, \ldots, 30 \%)$, foi determinado por processo iterativo até a convergência. O tamanho ótimo de parcela para avaliar a massa verde de aveia preta é de 4,14UEB de $1 \mathrm{~m}^{2}$ (4,14m²). Quatro repetições, para avaliar até 50 tratamentos, nos delineamentos inteiramente casualizado e blocos ao acaso, são suficientes para identificar, como significativas a 5\% de probabilidade, pelo teste de Tukey, diferenças entre médias de tratamentos de $26,7 \%$ da média do experimento.

Palavras-chave: Avena strigosa Schreb, planejamento experimental, precisão experimental.

\section{ABSTRACT}

The objectives of this research were to determine the optimum plot size and number of repetitions, to evaluate the fresh weight of black oat (Avena strigosa Schreb). Eighteen uniformity assays of $8 m \times 8 m\left(64 m^{2}\right)$ were conducted. Each assay was divided in 64 basic experimental units (UEB) of $1 \mathrm{~m} \times 1 \mathrm{~m}$, totaling $1,152 \mathrm{UEB}$. The fresh weight of plants, in each UEB was weighed. Nine assays (576UEB) were evaluated at 102 days after sowing and the other nine assays (576UEB) at 106 days after sowing. The optimum plot size $(X o)$ was determined by the method of maximum curvature of the model coefficient of variation and the means compared, among evaluation times, by Student's t test. The number of repetitions for experiments on completely randomized and randomized block designs, in scenarios of combinations of $i$ treatments $(i=3,4, \ldots$, $50)$ and d minimal differences between treatments means, to be detected as significant, 5\% probability by Tukey test, expressed in percentage of the average of the experiment $(d=10 \%, 12 \%$, ..., 30\%), was determined by iterative process until convergence. The optimum plot size to evaluate the fresh weight of black oats is 4.14 UEB of $1 \mathrm{~m}^{2}\left(4.14 \mathrm{~m}^{2}\right)$. Four replications, to evaluate up to 50 treatments, in completely randomized and randomized block designs, are sufficient to identify, as significant at $5 \%$ probability by Tukey test, differences between treatment means of $26.7 \%$ of the average experiment.

Key words: Avena strigosa Schreb, experimental design, experimental precision.

\section{INTRODUÇÃO}

A aveia preta (Avena strigosa Schreb) é a principal cultura de cobertura de solo, utilizada na região Sul do Brasil, na entressafra das culturas comerciais de verão (SANTI et al., 2003) e é uma das gramíneas de inverno mais cultivadas no Rio Grande do Sul (DEBIASI et al., 2007). A cultura é utilizada

'Departamento de Fitotecnia, Centro de Ciências Rurais (CCR), Universidade Federal de Santa Maria (UFSM), 97105-900, Santa Maria,

RS, Brasil. E-mail: alberto.cargnelutti.filho@gmail.com. Autor para correspondência.

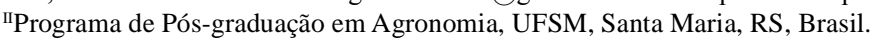

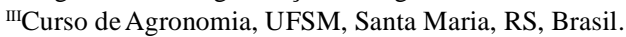


em sistemas de sucessão ou rotação de culturas, por apresentar menor velocidade de decomposição da palhada e liberação gradual de nutrientes, em relação a outras plantas de cobertura (CRUSCIOL et al., 2008), apresentando também elevada produção de massa verde e capacidade de proteção do solo (MARTINS et al., 2008; SOUZA et al., 2009). Ainda, de acordo com SALGADO et al. (2013), a utilização de aveia preta como planta forrageira, na alimentação de vacas leiteiras, aumenta o volume de leite produzido e reduz os custos, em relação à utilização de outras dietas volumosas.

Para que os resultados obtidos em experimentos com plantas de cobertura ou forrageiras sejam precisos, é necessário dimensionar adequadamente o tamanho ótimo de parcela e o número de repetições a ser utilizado. Para avaliar o efeito da adubação nitrogenada sobre a produção de fitomassa de aveia preta, SANTI et al. (2003) utilizaram parcelas de $25 \mathrm{~m}^{2}(5 \mathrm{~m} \times 5 \mathrm{~m})$, com área útil de $16 \mathrm{~m}^{2}$. $\mathrm{Na}$ avaliação da taxa de decomposição e liberação de macronutrientes da cultura, CRUSCIOL et al. (2008) utilizaram parcelas de $60 \mathrm{~m}^{2}(6 \mathrm{~m} \times 10 \mathrm{~m})$, sendo posteriormente coletada a fitomassa de três amostras de $1 \mathrm{~m}^{2}$ por parcela. Em estudo desenvolvido por TORRES et al. (2008), para a avaliação da produção de fitomassa e mineralização dos resíduos de aveia preta e outras plantas de cobertura, foram utilizadas parcelas de $40 \mathrm{~m}^{2}(4 \mathrm{~m} \times 10 \mathrm{~m})$, sendo posteriormente coletadas duas amostras, em uma área de $1 \mathrm{~m}^{2}$ por parcela. $\mathrm{Na}$ avaliação do desempenho agronômico de aveia preta e de outras cinco plantas de cobertura, CARVALHO et al. (2013) utilizaram parcelas de $16 \mathrm{~m}^{2}(4 \mathrm{~m} \times 4 \mathrm{~m})$, com área útil de $9 \mathrm{~m}^{2}$. Para avaliar os efeitos da densidade e da velocidade de semeadura sobre a produtividade de grãos, componentes do rendimento da aveia preta (DEBIASI et al., 2007) e sobre o crescimento da aveia preta (MARTINS et al. , 2008) foram utilizadas subparcelas de $154 \mathrm{~m}^{2}$ $(2,2 \mathrm{~m} \times 70 \mathrm{~m})$ sendo as avaliações realizadas na área central de $42 \mathrm{~m}^{2}(1,4 \mathrm{~m} \times 30 \mathrm{~m})$. Em relação ao número de repetições, DEBIASI et al. (2007) e MARTINS et al. (2008) utilizaram três repetições, enquanto SANTI et al. (2003), CRUSCIOL et al. (2008), TORRES et al. (2008) e CARVALHO et al. (2013) utilizaram quatro repetições, no delineamento blocos ao acaso.

O tamanho ótimo de parcela pode ser determinado a partir de dados obtidos em experimentos em branco, denominados ensaios de uniformidade, sobre os quais não são aplicados tratamentos (RAMALHO et al., 2005; STORCK et al., 2011). O método da curvatura máxima do modelo do coeficiente de variação (PARANAÍBA et al., 2009) é um dos métodos utilizados para a determinação do tamanho ótimo de parcela, tendo sido utilizado por CARGNELUTTI FILHO et al. (2011), no dimensionamento do tamanho ótimo de parcela para a mensuração da massa verde de nabo forrageiro. No entanto, em outras plantas de cobertura de solo, como a aveia preta, investigações sobre o tamanho ótimo de parcela e o número de repetições, para avaliar a massa verde, não foram encontradas na literatura. Assim, os objetivos deste trabalho foram determinar o tamanho ótimo de parcela e o número de repetições, a fim de avaliar a massa verde de aveia preta (Avena strigosa Schreb).

\section{MATERIAL E MÉTODOS}

Foram conduzidos 18 ensaios de uniformidade (experimentos em branco) com a cultura de aveia preta (Avena strigosa Schreb, cv. comum), numa área experimental de $60 \mathrm{~m} \times 60 \mathrm{~m}$ do Departamento de Fitotecnia da Universidade Federal de Santa Maria, Santa Maria, Estado do Rio Grande do Sul, a 2942'S, 534' W e a $95 \mathrm{~m}$ de altitude. A semeadura de aveia preta, na área experimental, foi realizada a lanço em 14 de junho de 2012 e a densidade obtida foi de 364 plantas $\mathrm{m}^{-2}$. Conforme preconizado para ensaios de uniformidade, realizaram-se os tratos culturais de forma homogênea, em toda a área experimental (RAMALHO et al., 2005; STORCK et al., 2011).

Cada ensaio de uniformidade de tamanho $8 \mathrm{~m} \times 8 \mathrm{~m} \quad\left(64 \mathrm{~m}^{2}\right)$ foi dividido em 64 unidades experimentais básicas (UEB) de $1 \mathrm{~m} \times 1 \mathrm{~m} \quad\left(1 \mathrm{~m}^{2}\right)$, formando uma matriz de oito linhas e oito colunas. Em nove ensaios aos 102 dias após a semeadura (primeira época de avaliação) e em nove ensaios aos 106 dias após a semeadura (segunda época de avaliação), em cada UEB, foram cortadas as plantas, junto à superfície do solo, e pesada a massa verde, em gramas $\mathrm{m}^{-2}$.

Para cada ensaio de uniformidade, com os dados de massa verde das 64UEB, foram determinados o coeficiente de autocorrelação espacial de primeira ordem $(\rho)$, a variância $\left(\mathrm{s}^{2}\right)$, a média (m) e o coeficiente de variação do ensaio (CV), em percentagem. A estimativa de $\rho$ foi obtida no sentido das linhas, conforme metodologia de PARANAÍBA et al. (2009). Para isso, iniciou-se o caminhamento a partir da UEB localizada na linha 1 , coluna 1 , até a linha 1 , coluna 8 , retornando a partir da linha 2 , coluna 8 , até a linha 2 , coluna 1 , e, assim, sucessivamente até completar o caminhamento na UEB localizada na linha 8, coluna 1. Após, em cada um dos 18 ensaios, foi determinado o tamanho ótimo de parcela (Xo) pelo método da curvatura máxima do modelo do coeficiente de variação, por meio da expressão 
$\mathrm{Xo}=\frac{10 \sqrt[3]{2\left(1-\rho^{2}\right) \mathrm{s}^{2} \mathrm{~m}}}{\mathrm{~m}}$ (PARANAÍBA et al., 2009).

A seguir, foi determinado o coeficiente de variação no tamanho ótimo de parcela $\left(\mathrm{CV}_{\mathrm{Xo}}\right)$, em percentagem, por meio da expressão $\mathrm{CV}_{\mathrm{Xo}}=\frac{\sqrt{\left(1-\rho^{2}\right) \mathrm{s}^{2} / \mathrm{m}^{2}}}{\sqrt{\mathrm{Xo}}} \times 100$

(PARANAÍBA et al., 2009). Assim, para cada uma das épocas de avaliação, foram obtidas nove estimativas das estatísticas $\rho, \mathrm{s}^{2}, \mathrm{~m}, \mathrm{CV}, \mathrm{Xo}$ e $\mathrm{CV}_{\mathrm{X}}$.

A seguir, para as nove estimativas de cada estatística $\left(\rho, s^{2}, m, C V\right.$, Xo e $\left.\mathrm{CV}_{\mathrm{Xo}}\right)$, de cada época de avaliação, foram calculadas a média, o desvio padrão, o coeficiente de variação e o valor-p do teste de normalidade de Kolmogorov-Smirnov. A comparação das médias das estatísticas $\rho, \mathrm{s}^{2}, \mathrm{~m}, \mathrm{CV}$, Xo e $\mathrm{CV}_{\mathrm{Xo}_{\mathrm{o}}}$ entre as épocas de avaliação ( $\mathrm{n}=9$ ensaios de uniformidade por época) foi realizada por meio do teste t de Student para amostras independentes, a $5 \%$ de probabilidade.

A diferença mínima significativa (d) do teste de Tukey, expressa em percentagem da média do experimento, é estimada pela expressão $\mathrm{d}=\frac{\mathrm{q}_{\alpha(\mathrm{i}, \mathrm{GLE})} \sqrt{\frac{\mathrm{QME}}{\mathrm{r}}}}{\mathrm{m}} \times 100$ em que $\mathrm{q}_{\alpha(\mathrm{i} ; \mathrm{GLE})}$ é o valor crítico do teste de Tukey em nível $\alpha$ de probabilidade de erro $(\alpha=0,05$, nesse estudo), i é o número de tratamentos, GLE é o número de graus de liberdade do erro, ou seja, i (r-1) para o delineamento inteiramente casualizado e (i-1)(r-1) para o delineamento blocos ao acaso, QME é o quadrado médio do erro, $\mathrm{r}$ é o número de repetições e m é a média do experimento. Substituindo a expressão do coeficiente de variação experimental $\left(\mathrm{CV}=\frac{\sqrt{\mathrm{QME}}}{\mathrm{m}} \times 100\right)$, em percentagem, na expressão para o cálculo de $\mathrm{d}$ e isolando $\mathrm{r}$ tem-se $\mathrm{r}=\left(\frac{\mathrm{q}_{\mathrm{o(i \textrm {i } G L E )}} \mathrm{CV}}{\mathrm{d}}\right)^{2}$. Neste estudo, o CV é expresso em percentagem e corresponde ao $\mathrm{CV}_{\mathrm{Xo}}$, pois esse é o $\mathrm{CV}$ esperado para o experimento com o tamanho ótimo de parcela (Xo) determinado. A seguir, a partir do $\mathrm{CV}_{\mathrm{Xo}}$ médio das duas épocas de avaliação, determinou-se o número de repetições (r), por processo iterativo até a convergência, para experimentos nos delineamentos inteiramente casualizado e blocos ao acaso, em cenários formados pelas combinações de $\mathrm{i}(\mathrm{i}=3,4, \ldots$, 50) e $\mathrm{d}(\mathrm{d}=10 \%, 12 \%, \ldots, 30 \%)$. Menores valores de d indicam maior precisão experimental, ou seja, menores diferenças entre médias de tratamentos serão consideradas significativas e vice-versa. As análises estatísticas foram realizadas com auxílio do aplicativo Microsoft Office Excel e dos softwares R
(R DEVELOPMENT CORE TEAM, 2013) e Genes (CRUZ, 2006).

\section{RESULTADOS E DISCUSSÃO}

Emrelação aos dados de massaverde de aveia preta (Avena strigosa Schreb), houve variabilidade das estimativas do coeficiente de autocorrelação espacial de primeira ordem $(\rho)$, da variância $\left(\mathrm{s}^{2}\right)$, da média $(\mathrm{m})$ e do coeficiente de variação do ensaio $(\mathrm{CV})$, entre os nove ensaios de uniformidade, em cada época de avaliação (Tabela 1). Consequentemente, houve variabilidade nas estimativas do tamanho ótimo de parcela (Xo) e do coeficiente de variação no tamanho ótimo de parcela $\left(\mathrm{CV}_{\mathrm{Xo}}\right)$. Essa variabilidade é explicada pelo fato de que, no método da curvatura máxima do modelo do coeficiente de variação (PARANAÍBA et al., 2009), as estimativas Xo e $\mathrm{CV}_{\mathrm{Xo}}$ são calculadas com base em $\rho, \mathrm{s}^{2}$ e m. Esse cenário de variabilidade das estatísticas $\rho, \mathrm{s}^{2}, \mathrm{~m}, \mathrm{CV}$, $\mathrm{Xo}$ e $\mathrm{CV}_{\mathrm{Xo}}$, entre os nove ensaios, em cada época de avaliação, é particularmente importante, para o estudo do dimensionamento de tamanho de parcela e do número de repetições, e reflete condições reais de áreas de campo. As estatísticas $\rho, \mathrm{s}^{2}, \mathrm{~m}$, $\mathrm{CV}$, Xo e $\mathrm{CV}_{\mathrm{Xo}}$, nas duas épocas de avaliação, apresentaram boa aderência à distribuição normal ( $\mathrm{P} \geq 0,698$ na primeira época de avaliação e $\mathrm{P} \geq 0,361$ na segunda época de avaliação), de acordo com o teste de Kolmogorov-Smirnov, o que indica que as inferências com base na média dos nove ensaios são adequadas.

A massa verde de aveia preta, na área onde foram avaliadas as 576 unidades experimentais básicas (UEB), aos 106 dias após a semeadura (DAS) $\left(2.364,83 \mathrm{~g} \mathrm{~m}^{-2}\right)$, foi maior que na área onde foram avaliadas as outras 576UEB, aos 102DAS $(2.164,90 \mathrm{~g}$ $\mathrm{m}^{-2}$ ). A produção obtida nas duas épocas de avaliação (102 e 106 dias após a semeadura) foi superior à verificada por MARTINS et al. (2008), que obtiveram uma produção média de massa verde de aveia preta, de $11.934 \mathrm{~kg} \mathrm{ha}^{-1}$, aos 70 dias após a semeadura. Os autores também verificaram produção de massa verde de $17.578 \mathrm{~kg} \mathrm{ha}^{-1}$, aos 45 dias após o pastejo. Ainda, a produção de massa verde de aveia preta superou a massa verde de $6.623 \mathrm{~kg} \mathrm{ha}^{-1}$, avaliada aos 100 dias após a semeadura, no estudo de MAULI et al. (2011). Já SOUZA et al. (2009) avaliaram a produção de massa verde de aveia preta em cinco épocas (7, $14,21,28$ e 35 dias após o corte) e verificaram que a massa verde oscilou entre 15.650 e $23.430 \mathrm{~kg} \mathrm{ha}^{-1}$, com média de $19.780 \mathrm{~kg} \mathrm{ha}^{-1}$. Os maiores valores de massa verde obtidos no presente estudo podem estar 
Tabela 1 - Coeficiente de autocorrelação espacial de primeira ordem $(\rho)$, variância $\left(\mathrm{s}^{2}\right)$, média $(\mathrm{m})$, coeficiente de variação do ensaio $(\mathrm{CV}$, em \%), tamanho ótimo de parcela $\left(\mathrm{Xo}, \mathrm{em} \mathrm{m}^{2}\right)$ e coeficiente de variação no tamanho ótimo de parcela $\left(\mathrm{CV}_{\mathrm{Xo}}\right.$, em \%), para a massa verde de aveia preta (Avena strigosa Schreb), em gramas por unidade experimental básica de $1 \mathrm{~m} \times 1 \mathrm{~m}\left(1 \mathrm{~m}^{2}\right)$, em nove ensaios de uniformidade avaliados aos 102 dias após a semeadura (primeira época) e em nove ensaios de uniformidade, avaliados aos 106 dias após a semeadura (segunda época).

\begin{tabular}{|c|c|c|c|c|c|c|}
\hline Ensaio $^{(1)}$ e estatística & $\rho$ & $\mathrm{s}^{2}$ & $\mathrm{~m}$ & $\mathrm{CV}(\%)$ & $\mathrm{Xo}\left(\mathrm{m}^{2}\right)$ & $\mathrm{CV}_{\mathrm{Xo}}(\%)$ \\
\hline 1 & 0,47 & $200.070,61$ & $2.165,34$ & 20,66 & 4,05 & 9,05 \\
\hline 2 & 0,57 & $149.109,06$ & $2.162,05$ & 17,86 & 3,51 & 7,84 \\
\hline 3 & 0,49 & $183.757,81$ & $2.297,89$ & 18,65 & 3,75 & 8,39 \\
\hline 4 & 0,21 & $222.511,10$ & $2.272,59$ & 20,76 & 4,35 & 9,73 \\
\hline 5 & $-0,01$ & $188.283,27$ & $2.167,48$ & 20,02 & 4,31 & 9,64 \\
\hline 6 & 0,14 & $104.665,90$ & $2.276,14$ & 14,21 & 3,41 & 7,62 \\
\hline 7 & 0,34 & $251.591,19$ & $2.126,17$ & 23,59 & 4,62 & 10,33 \\
\hline 8 & 0,71 & $319.318,12$ & $1.985,56$ & 28,46 & 4,32 & 9,66 \\
\hline 9 & 0,65 & $390.063,04$ & $2.030,86$ & 30,75 & 4,79 & 10,72 \\
\hline Mínimo & $-0,01$ & $104.665,90$ & $1.985,56$ & 14,21 & 3,41 & 7,62 \\
\hline Máximo & 0,71 & $390.063,04$ & $2.297,89$ & 30,75 & 4,79 & 10,72 \\
\hline Média ${ }^{(2)}$ & $0,40 \mathrm{a}$ & $223.263,35 \mathrm{a}$ & $2.164,90 \mathrm{~b}$ & $21,66 \mathrm{a}$ & $4,12 \mathrm{a}$ & $9,22 \mathrm{a}$ \\
\hline Desvio padrão & 0,24 & $87.133,59$ & 107,99 & 5,20 & 0,48 & 1,08 \\
\hline Coeficiente de variação $(\%)$ & 61,50 & 39,03 & 4,99 & 23,99 & 11,68 & 11,68 \\
\hline Valor-p $\mathrm{p}^{(3)}$ & 0,937 & 0,957 & 0,948 & 0,698 & 0,833 & 0,833 \\
\hline & $-----S e$ & ca de avaliaçã & 6 dias após a & adura-----. & 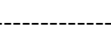 & -------- \\
\hline 1 & 0,46 & $233.826,14$ & $2.356,38$ & 20,52 & 4,05 & 9,05 \\
\hline 2 & 0,31 & $248.237,93$ & $2.470,09$ & 20,17 & 4,19 & 9,37 \\
\hline 3 & 0,24 & $158.459,63$ & $2.342,22$ & 17,00 & 3,79 & 8,47 \\
\hline 4 & 0,08 & $229.845,49$ & $2.113,75$ & 22,68 & 4,67 & 10,45 \\
\hline 5 & $-0,04$ & $177.458,13$ & $2.281,47$ & 18,46 & 4,08 & 9,13 \\
\hline 6 & 0,10 & $164.442,37$ & $2.338,70$ & 17,34 & 3,90 & 8,73 \\
\hline 7 & 0,42 & $457.874,14$ & $2.449,17$ & 27,63 & 5,01 & 11,19 \\
\hline 8 & 0,38 & $189.598,92$ & $2.475,11$ & 17,59 & 3,75 & 8,40 \\
\hline 9 & 0,35 & $206.330,19$ & $2.456,56$ & 18,49 & 3,92 & 8,76 \\
\hline Mínimo & $-0,04$ & $158.459,63$ & $2.113,75$ & 17,00 & 3,75 & 8,40 \\
\hline Máximo & 0,46 & $457.874,14$ & $2.475,11$ & 27,63 & 5,01 & 11,19 \\
\hline Média $^{(2)}$ & $0,26 \mathrm{a}$ & $229.563,66 \mathrm{a}$ & $2.364,83 \mathrm{a}$ & $19,99 \mathrm{a}$ & $4,15 \mathrm{a}$ & $9,28 \mathrm{a}$ \\
\hline Desvio padrão & 0,17 & $91.269,64$ & 117,27 & 3,40 & 0,42 & 0,94 \\
\hline Coeficiente de variação (\%) & 67,44 & 39,76 & 4,96 & 16,99 & 10,17 & 10,17 \\
\hline Valor- $\mathrm{p}^{(3)}$ & 0,950 & 0,361 & 0,829 & 0,748 & 0,677 & 0,677 \\
\hline
\end{tabular}

${ }^{(1)}$ Cada ensaio de uniformidade de tamanho $8 \mathrm{~m} \times 8 \mathrm{~m}\left(64 \mathrm{~m}^{2}\right)$ foi dividido em 64 unidades experimentais básicas de $1 \mathrm{~m} \times 1 \mathrm{~m}\left(1 \mathrm{~m}^{2}\right)$, formando uma matriz de oito linhas e oito colunas. ${ }^{(2)}$ Para cada estatística $\left(\rho, s^{2}, m, C V\right.$, Xo e $\left.C_{X_{\mathrm{Xo}}}\right)$, as médias não seguidas por mesma letra na coluna (comparação de médias entre as épocas de avaliação) diferem a 5\% de probabilidade pelo teste t de Student para amostras independentes, com 16 graus de liberdade. ${ }^{(3)}$ Teste de normalidade de Kolmogorov-Smirnov.

relacionados ao maior período compreendido entre a semeadura e o momento de mensuração da massa verde, quando comparado aos estudos de MARTINS et al. (2008) e SOUZA et al. (2009). A alta produção de massa verde, aliada ao elevado conjunto de dados (1.152UEB) e ao cenário de ampla variabilidade conferem credibilidade ao estudo proposto.

Embora a massa verde tenha sido maior aos 106 DAS, quando comparada à avaliação realizada aos 102 DAS, não houve diferença significativa de $\rho$, $\mathrm{s}^{2}, \mathrm{CV}, \mathrm{Xo}$ e $\mathrm{CV}_{\mathrm{Xo}}$ entre as duas épocas de avaliação
(Tabela 1). Assim, os seguintes valores médios: $\rho=0,33, s^{2}=226.413,50, C V=20,82 \%, X o=4,14 U E B$ e $\mathrm{CV}_{\mathrm{Xo}}=9,25 \%$ são adequados para representar as duas épocas de avaliação.Dessa forma, em relação ao $\rho=0,33$, deve-se interpretar que, para valores fixos de $\mathrm{s}^{2}$ e $\mathrm{m}$, quanto mais próximo de 1 (autocorrelação espacial positiva) ou de -1 (autocorrelação espacial negativa) for o $\rho$, maior a dependência entre os valores das unidades experimentais básicas adjacentes e, consequentemente, menor será a estimativa de Xo pela equação de PARANAÍBA et al. (2009). Por 
outro lado, quando $\rho$ for igual a zero, há ausência de autocorrelação espacial e, por consequência, o Xo é máximo, pois as unidades experimentais básicas seriam independentes.

Verificou-se que o tamanho ótimo de parcela para avaliar a massa verde de aveia preta foi de 4,14 unidades experimentais básicas de $1 \mathrm{~m}^{2}$ $\left(4,14 \mathrm{~m}^{2}\right)$ e o coeficiente de variação no tamanho ótimo de parcela foi $9,25 \%$. Os tamanhos de parcela utilizados por SANTI et al. (2003), DEBIASI et al. (2007), CRUSCIOL et al. (2008), MARTINS et al. (2008), TORRES et al. (2008) e CARVALHO et al. (2013) foram superiores aos obtidos no presente estudo, sugerindo confiabilidade nas informações publicadas. No entanto, deve-se salientar que a área da parcela efetivamente utilizada por CRUSCIOL et al. (2008) e por TORRES et al. (2008) para a mensuração das variáveis foi inferior a $4,14 \mathrm{~m}^{2}$. Além disso, é importante destacar que a comparação entre o tamanho ótimo de parcela obtido neste estudo e os tamanhos de parcela utilizados nos trabalhos citados deve ser vista com cautela, em função da diferença de manejo, das variáveis analisadas e da avaliação de outras culturas, juntamente com a aveia preta, em alguns dos trabalhos supracitados. Não foram encontrados estudos de tamanho ótimo de parcela para avaliar a massa verde de aveia preta para serem comparados com os obtidos neste estudo. Em trigo, cultura da família das gramíneas como a aveia preta, HENRIQUES NETO et al. (2009) encontraram tamanhos de parcela que variaram entre 0,43 e $4,80 \mathrm{~m}^{2}$, de acordo com o sistema de semeadura, a cultivar e o método de estimação. Em nabo forrageiro, cultura de cobertura de solo como a aveia preta, o tamanho ótimo de parcela, para avaliar a massa verde, determinado por CARGNELUTTI FILHO et al. (2011), foi de 4,82 unidades experimentais básicas de $0,25 \mathrm{~m}^{2}\left(1,20 \mathrm{~m}^{2}\right)$.

O número de repetições, para experimentos no delineamento inteiramente casualizado (DIC), em cenários formados pelas combinações de i tratamentos $(\mathrm{i}=3,4, \ldots, 50)$ e d diferenças mínimas entre médias de tratamentos a serem detectadas como significativas a $5 \%$ de probabilidade, pelo teste de Tukey, expressas em percentagem da média do experimento $(\mathrm{d}=10 \%$, $12 \%, \ldots, 30 \%)$, para avaliar a massa verde de aveia preta, oscilou entre 2,48 (três tratamentos e d=30\%) e 27,41 (50 tratamentos e d=10\%) (Tabela 2). Já para experimentos no delineamento blocos ao acaso (DBA), o número de repetições variou entre 2,56 (três tratamentos e d=30\%) e 27,42 (50 tratamentos e $\mathrm{d}=10 \%$ ) (Tabela 3). Portanto, mesmo com coeficiente de variação de 9,25\%, classificado como baixo (PIMENTEL-GOMES, 1990), independentemente do delineamento experimental, obter precisão de $10 \%$ (maior precisão) é impraticável pelo elevado número de repetições necessário. Não cabe aqui o julgamento de qual a precisão que deve ser adotada, ficando essa tarefa ao usuário dessas informações, que, com base no $\mathrm{Xo}=4,14 \mathrm{~m}^{2}$, pode estabelecer a relação entre $\mathrm{i}, \mathrm{d}$ e número de repetições possível de ser realizada.

Independentemente do delineamento experimental (inteiramente casualizado ou blocos ao acaso), para valores fixos de $\mathrm{d} \mathrm{e}_{\mathrm{CV}_{\mathrm{Xo}}}$, há aumento do número de repetições (r) com o acréscimo do número de tratamentos (Tabelas 2 e 3). Como esperado, para valores fixos de i e d, são necessárias mais repetições no DBA em relação ao DIC, o que comprova a maior eficiência do DIC em relação ao DBA, quando as unidades experimentais (parcelas) são homogêneas (STORCK et al., 2011). Por exemplo, para $\mathrm{i}=3 \mathrm{e}$ $\mathrm{d}=10 \%$, precisariam 10,95 repetições no DBA e 10,46 no DIC. Para o mesmo d, a diferença entre o número de repetições entre os delineamentos diminui com o acréscimo do número de tratamentos. Portanto, quando o número de tratamentos é alto, o número de repetições para o DBA e para o DIC é próximo. Assim, por exemplo, para avaliar i=50 e $\mathrm{d}=30 \%$, precisariam 3,22 repetições no DBA e 3,21 no DIC.

$\mathrm{Na}$ prática, não é possível realizar 3,22 ou 3,21 repetições. Então, fixando-se $r$ igual a quatro repetições, conforme utilizado nos experimentos realizados por SANTI et al. (2003), CRUSCIOL et al. (2008), TORRES et al. (2008) e CARVALHO et al. (2013), a diferença mínima significativa (d) do teste de Tukey, expressa em percentagem da média do experimento, é estimada pela expressão: $\quad d=\frac{q_{\alpha(i, G L E)} C V}{\sqrt{r}}$. Assim, com 50 tratamentos, para odelineamento inteiramente casualizado

$$
\mathrm{d}=\frac{\mathrm{q}_{5 \%(50 ; 150)} \times 9,25}{\sqrt{4}}=\frac{5,7710567 \times 9,25}{\sqrt{4}}=26,69 \%
$$

e para o delineamento blocos ao acaso

$$
\mathrm{d}=\frac{\mathrm{q}_{5 \%(50 ; 147)} \times 9,25}{\sqrt{4}}=\frac{5,7736023 \times 9,25}{\sqrt{4}}=26,70 \% .
$$

Então, pode-se inferir que, para avaliar massa verde de aveia preta nos delineamentos inteiramente casualizado e blocos ao acaso com até 50 tratamentos, quatro repetições são suficientes para identificar, como significativas a $5 \%$ de probabilidade, pelo teste de Tukey, diferenças entre médias de tratamentos de $26,7 \%$ da média do experimento. 
Tabela 2 - Número de repetições, para experimentos no delineamento inteiramente casualizado, em cenários formados pelas combinações de i tratamentos $(\mathrm{i}=3,4, \ldots, 50)$ e d diferenças mínimas entre médias de tratamentos a serem detectadas como significativas a $5 \%$ de probabilidade, pelo teste de Tukey, expressas em percentagem da média do experimento (d=10\%, 12\%, ..., 30\%), para avaliar a massa verde de aveia preta (Avena strigosa Schreb), a partir de tamanho ótimo de parcela $\left(\mathrm{Xo}=4,14 \mathrm{~m}^{2}\right)$ e coeficiente de variação no tamanho ótimo de parcela $\left(\mathrm{CV}_{\mathrm{X}_{0}}=9,25 \%\right)$.

\begin{tabular}{|c|c|c|c|c|c|c|c|c|c|c|c|}
\hline i & $10 \%$ & $12 \%$ & $14 \%$ & $16 \%$ & $18 \%$ & $20 \%$ & $22 \%$ & $24 \%$ & $26 \%$ & $28 \%$ & $30 \%$ \\
\hline 3 & 10,46 & 7,61 & 5,91 & 4,81 & 4,07 & 3,53 & 3,16 & 2,98 & 4,08 & 2,62 & 2,48 \\
\hline 4 & 12,18 & 8,75 & 6,69 & 5,37 & 4,47 & 3,83 & 3,37 & 3,01 & 2,77 & 2,62 & 2,48 \\
\hline 5 & 13,50 & 9,63 & 7,30 & 5,80 & 4,78 & 4,06 & 3,53 & 3,14 & 2,84 & 2,62 & 2,48 \\
\hline 6 & 14,58 & 10,35 & 7,80 & 6,16 & 5,04 & 4,25 & 3,67 & 3,23 & 2,91 & 2,65 & 2,48 \\
\hline 7 & 15,49 & 10,95 & 8,23 & 6,47 & 5,27 & 4,41 & 3,79 & 3,32 & 2,96 & 2,69 & 2,48 \\
\hline 8 & 16,28 & 11,48 & 8,60 & 6,74 & 5,46 & 4,56 & 3,90 & 3,40 & 3,02 & 2,73 & 2,49 \\
\hline 9 & 16,98 & 11,96 & 8,93 & 6,98 & 5,64 & 4,70 & 4,00 & 3,48 & 3,08 & 2,77 & 2,52 \\
\hline 10 & 17,60 & 12,38 & 9,23 & 7,20 & 5,81 & 4,82 & 4,09 & 3,55 & 3,13 & 2,80 & 2,54 \\
\hline 11 & 18,17 & 12,76 & 9,51 & 7,40 & 5,96 & 4,93 & 4,18 & 3,61 & 3,18 & 2,84 & 2,57 \\
\hline 12 & 18,69 & 13,11 & 9,76 & 7,58 & 6,10 & 5,04 & 4,26 & 3,68 & 3,22 & 2,87 & 2,59 \\
\hline 13 & 19,17 & 13,44 & 9,99 & 7,75 & 6,23 & 5,14 & 4,34 & 3,73 & 3,27 & 2,91 & 2,62 \\
\hline 14 & 19,62 & 13,74 & 10,20 & 7,91 & 6,35 & 5,23 & 4,41 & 3,79 & 3,31 & 2,94 & 2,64 \\
\hline 15 & 20,03 & 14,03 & 10,41 & 8,06 & 6,46 & 5,32 & 4,48 & 3,84 & 3,35 & 2,97 & 2,67 \\
\hline 16 & 20,42 & 14,29 & 10,60 & 8,20 & 6,57 & 5,40 & 4,54 & 3,89 & 3,39 & 3,00 & 2,69 \\
\hline 17 & 20,79 & 14,54 & 10,78 & 8,34 & 6,67 & 5,48 & 4,60 & 3,94 & 3,43 & 3,03 & 2,71 \\
\hline 18 & 21,13 & 14,78 & 10,94 & 8,46 & 6,76 & 5,55 & 4,66 & 3,99 & 3,47 & 3,06 & 2,73 \\
\hline 19 & 21,46 & 15,00 & 11,11 & 8,58 & 6,85 & 5,62 & 4,72 & 4,03 & 3,50 & 3,08 & 2,75 \\
\hline 20 & 21,77 & 15,21 & 11,26 & 8,70 & 6,94 & 5,69 & 4,77 & 4,07 & 3,53 & 3,11 & 2,77 \\
\hline 21 & 22,07 & 15,41 & 11,40 & 8,80 & 7,03 & 5,76 & 4,82 & 4,11 & 3,57 & 3,14 & 2,79 \\
\hline 22 & 22,35 & 15,61 & 11,54 & 8,91 & 7,10 & 5,82 & 4,87 & 4,15 & 3,60 & 3,16 & 2,81 \\
\hline 23 & 22,63 & 15,79 & 11,68 & 9,01 & 7,18 & 5,88 & 4,92 & 4,19 & 3,63 & 3,18 & 2,83 \\
\hline 24 & 22,89 & 15,97 & 11,81 & 9,10 & 7,26 & 5,94 & 4,96 & 4,23 & 3,66 & 3,21 & 2,85 \\
\hline 25 & 23,13 & 16,14 & 11,93 & 9,20 & 7,33 & 5,99 & 5,01 & 4,26 & 3,68 & 3,23 & 2,87 \\
\hline 26 & 23,37 & 16,31 & 12,05 & 9,29 & 7,39 & 6,04 & 5,05 & 4,30 & 3,71 & 3,25 & 2,89 \\
\hline 27 & 23,61 & 16,47 & 12,16 & 9,37 & 7,46 & 6,10 & 5,09 & 4,33 & 3,74 & 3,27 & 2,90 \\
\hline 28 & 23,83 & 16,62 & 12,27 & 9,45 & 7,52 & 6,15 & 5,13 & 4,36 & 3,76 & 3,29 & 2,92 \\
\hline 29 & 24,04 & 16,77 & 12,38 & 9,53 & 7,59 & 6,20 & 5,17 & 4,39 & 3,79 & 3,32 & 2,94 \\
\hline 30 & 24,25 & 16,91 & 12,48 & 9,61 & 7,65 & 6,24 & 5,21 & 4,42 & 3,81 & 3,34 & 2,95 \\
\hline 31 & 24,45 & 17,05 & 12,58 & 9,69 & 7,70 & 6,29 & 5,24 & 4,45 & 3,84 & 3,35 & 2,97 \\
\hline 32 & 24,65 & 17,18 & 12,68 & 9,76 & 7,76 & 6,33 & 5,28 & 4,48 & 3,86 & 3,37 & 2,98 \\
\hline 33 & 24,84 & 17,31 & 12,77 & 9,83 & 7,82 & 6,38 & 5,31 & 4,51 & 3,88 & 3,39 & 3,00 \\
\hline 34 & 25,02 & 17,44 & 12,87 & 9,90 & 7,87 & 6,42 & 5,35 & 4,54 & 3,91 & 3,41 & 3,01 \\
\hline 35 & 25,20 & 17,56 & 12,95 & 9,97 & 7,92 & 6,46 & 5,38 & 4,56 & 3,93 & 3,43 & 3,03 \\
\hline 36 & 25,38 & 17,68 & 13,04 & 10,03 & 7,97 & 6,50 & 5,41 & 4,59 & 3,95 & 3,44 & 3,04 \\
\hline 37 & 25,55 & 17,80 & 13,13 & 10,10 & 8,02 & 6,54 & 5,44 & 4,61 & 3,97 & 3,46 & 3,06 \\
\hline 38 & 25,71 & 17,91 & 13,21 & 10,16 & 8,07 & 6,58 & 5,47 & 4,64 & 3,99 & 3,48 & 3,07 \\
\hline 39 & 25,87 & 18,02 & 13,29 & 10,22 & 8,11 & 6,61 & 5,50 & 4,66 & 4,01 & 3,49 & 3,08 \\
\hline 40 & 26,03 & 18,13 & 13,37 & 10,28 & 8,16 & 6,65 & 5,53 & 4,69 & 4,03 & 3,51 & 3,10 \\
\hline 41 & 26,18 & 18,23 & 13,44 & 10,33 & 8,21 & 6,68 & 5,56 & 4,71 & 4,05 & 3,53 & 3,11 \\
\hline 42 & 26,33 & 18,34 & 13,52 & 10,39 & 8,25 & 6,72 & 5,59 & 4,73 & 4,07 & 3,54 & 3,12 \\
\hline 43 & 26,48 & 18,44 & 13,59 & 10,45 & 8,29 & 6,75 & 5,62 & 4,75 & 4,09 & 3,56 & 3,13 \\
\hline 44 & 26,62 & 18,53 & 13,66 & 10,50 & 8,33 & 6,79 & 5,64 & 4,78 & 4,10 & 3,57 & 3,15 \\
\hline 45 & 26,76 & 18,63 & 13,73 & 10,55 & 8,37 & 6,82 & 5,67 & 4,80 & 4,12 & 3,59 & 3,16 \\
\hline 46 & 26,89 & 18,72 & 13,80 & 10,60 & 8,41 & 6,85 & 5,69 & 4,82 & 4,14 & 3,60 & 3,17 \\
\hline 47 & 27,03 & 18,82 & 13,87 & 10,65 & 8,45 & 6,88 & 5,72 & 4,84 & 4,15 & 3,61 & 3,18 \\
\hline 48 & 27,16 & 18,91 & 13,93 & 10,70 & 8,49 & 6,91 & 5,74 & 4,86 & 4,17 & 3,63 & 3,19 \\
\hline 49 & 27,29 & 18,99 & 14,00 & 10,75 & 8,53 & 6,94 & 5,77 & 4,88 & 4,19 & 3,64 & 3,20 \\
\hline 50 & 27,41 & 19,08 & 14,06 & 10,80 & 8,57 & 6,97 & 5,79 & 4,90 & 4,20 & 3,66 & 3,21 \\
\hline
\end{tabular}


Tabela 3 - Número de repetições, para experimentos no delineamento blocos ao acaso, em cenários formados pelas combinações de i tratamentos $(\mathrm{i}=3,4, \ldots, 50)$ e d diferenças mínimas entre médias de tratamentos a serem detectadas como significativas a $5 \%$ de probabilidade, pelo teste de Tukey, expressas em percentagem da média do experimento ( $\mathrm{d}=10 \%, 12 \%, \ldots, 30 \%)$, para avaliar a massa verde de aveia preta (Avena strigosa Schreb), a partir de tamanho ótimo de parcela $\left(\mathrm{Xo}=4,14 \mathrm{~m}^{2}\right)$ e coeficiente de variação no tamanho ótimo de parcela $\left(\mathrm{CV}_{\mathrm{Xo}}=9,25 \%\right)$.

\begin{tabular}{|c|c|c|c|c|c|c|c|c|c|c|c|}
\hline $\mathrm{i}$ & $10 \%$ & $12 \%$ & $14 \%$ & $16 \%$ & $18 \%$ & $20 \%$ & $22 \%$ & $24 \%$ & $26 \%$ & $28 \%$ & $30 \%$ \\
\hline 3 & 10,95 & 8,10 & 6,39 & 5,28 & 4,52 & 3,92 & 3,33 & 2,58 & 2,41 & 2,78 & 2,56 \\
\hline 4 & 12,46 & 9,03 & 6,97 & 5,65 & 4,74 & 4,10 & 3,63 & 3,23 & 2,97 & 2,78 & 2,57 \\
\hline 5 & 13,69 & 9,81 & 7,49 & 5,99 & 4,96 & 4,24 & 3,71 & 3,30 & 3,00 & 2,78 & 2,57 \\
\hline 6 & 14,71 & 10,48 & 7,94 & 6,29 & 5,17 & 4,38 & 3,80 & 3,36 & 3,02 & 2,78 & 2,57 \\
\hline 7 & 15,59 & 11,05 & 8,33 & 6,57 & 5,37 & 4,51 & 3,89 & 3,42 & 3,07 & 2,79 & 2,57 \\
\hline 8 & 16,35 & 11,56 & 8,68 & 6,82 & 5,54 & 4,64 & 3,98 & 3,49 & 3,10 & 2,80 & 2,58 \\
\hline 9 & 17,04 & 12,02 & 9,00 & 7,04 & 5,71 & 4,76 & 4,07 & 3,54 & 3,14 & 2,83 & 2,58 \\
\hline 10 & 17,65 & 12,43 & 9,29 & 7,25 & 5,86 & 4,87 & 4,15 & 3,60 & 3,19 & 2,86 & 2,60 \\
\hline 11 & 18,21 & 12,81 & 9,55 & 7,44 & 6,00 & 4,98 & 4,23 & 3,66 & 3,23 & 2,89 & 2,62 \\
\hline 12 & 18,73 & 13,15 & 9,79 & 7,62 & 6,14 & 5,08 & 4,30 & 3,72 & 3,27 & 2,91 & 2,64 \\
\hline 13 & 19,20 & 13,47 & 10,02 & 7,79 & 6,26 & 5,17 & 4,37 & 3,77 & 3,31 & 2,94 & 2,66 \\
\hline 14 & 19,64 & 13,77 & 10,23 & 7,94 & 6,38 & 5,26 & 4,44 & 3,82 & 3,34 & 2,97 & 2,68 \\
\hline 15 & 20,06 & 14,05 & 10,43 & 8,09 & 6,49 & 5,34 & 4,50 & 3,87 & 3,38 & 3,00 & 2,69 \\
\hline 16 & 20,44 & 14,31 & 10,62 & 8,23 & 6,59 & 5,42 & 4,57 & 3,92 & 3,42 & 3,03 & 2,71 \\
\hline 17 & 20,81 & 14,56 & 10,80 & 8,36 & 6,69 & 5,50 & 4,62 & 3,96 & 3,45 & 3,05 & 2,73 \\
\hline 18 & 21,15 & 14,79 & 10,96 & 8,48 & 6,78 & 5,57 & 4,68 & 4,01 & 3,49 & 3,08 & 2,75 \\
\hline 19 & 21,48 & 15,02 & 11,12 & 8,60 & 6,87 & 5,64 & 4,73 & 4,05 & 3,52 & 3,10 & 2,77 \\
\hline 20 & 21,79 & 15,23 & 11,27 & 8,71 & 6,96 & 5,71 & 4,79 & 4,09 & 3,55 & 3,13 & 2,79 \\
\hline 21 & 22,08 & 15,43 & 11,42 & 8,82 & 7,04 & 5,77 & 4,83 & 4,13 & 3,58 & 3,15 & 2,81 \\
\hline 22 & 22,37 & 15,62 & 11,56 & 8,92 & 7,12 & 5,83 & 4,88 & 4,17 & 3,61 & 3,18 & 2,83 \\
\hline 23 & 22,64 & 15,81 & 11,69 & 9,02 & 7,19 & 5,89 & 4,93 & 4,20 & 3,64 & 3,20 & 2,85 \\
\hline 24 & 22,90 & 15,98 & 11,82 & 9,12 & 7,27 & 5,95 & 4,97 & 4,24 & 3,67 & 3,22 & 2,86 \\
\hline 25 & 23,14 & 16,15 & 11,94 & 9,21 & 7,34 & 6,00 & 5,02 & 4,27 & 3,70 & 3,24 & 2,88 \\
\hline 26 & 23,38 & 16,32 & 12,06 & 9,30 & 7,40 & 6,05 & 5,06 & 4,31 & 3,72 & 3,26 & 2,90 \\
\hline 27 & 23,61 & 16,47 & 12,17 & 9,38 & 7,47 & 6,11 & 5,10 & 4,34 & 3,75 & 3,28 & 2,91 \\
\hline 28 & 23,84 & 16,63 & 12,28 & 9,46 & 7,53 & 6,16 & 5,14 & 4,37 & 3,77 & 3,30 & 2,93 \\
\hline 29 & 24,05 & 16,77 & 12,39 & 9,54 & 7,59 & 6,20 & 5,18 & 4,40 & 3,80 & 3,32 & 2,95 \\
\hline 30 & 24,26 & 16,92 & 12,49 & 9,62 & 7,65 & 6,25 & 5,21 & 4,43 & 3,82 & 3,34 & 2,96 \\
\hline 31 & 24,46 & 17,05 & 12,59 & 9,69 & 7,71 & 6,30 & 5,25 & 4,46 & 3,85 & 3,36 & 2,98 \\
\hline 32 & 24,66 & 17,19 & 12,69 & 9,77 & 7,77 & 6,34 & 5,29 & 4,49 & 3,87 & 3,38 & 2,99 \\
\hline 33 & 24,85 & 17,32 & 12,78 & 9,84 & 7,82 & 6,38 & 5,32 & 4,51 & 3,89 & 3,40 & 3,01 \\
\hline 34 & 25,03 & 17,44 & 12,87 & 9,91 & 7,87 & 6,42 & 5,35 & 4,54 & 3,91 & 3,42 & 3,02 \\
\hline 35 & 25,21 & 17,57 & 12,96 & 9,97 & 7,93 & 6,46 & 5,39 & 4,57 & 3,93 & 3,43 & 3,03 \\
\hline 36 & 25,38 & 17,69 & 13,05 & 10,04 & 7,98 & 6,50 & 5,42 & 4,59 & 3,95 & 3,45 & 3,05 \\
\hline 37 & 25,55 & 17,80 & 13,13 & 10,10 & 8,03 & 6,54 & 5,45 & 4,62 & 3,98 & 3,47 & 3,06 \\
\hline 38 & 25,72 & 17,91 & 13,21 & 10,16 & 8,07 & 6,58 & 5,48 & 4,64 & 4,00 & 3,48 & 3,07 \\
\hline 39 & 25,88 & 18,02 & 13,29 & 10,22 & 8,12 & 6,62 & 5,51 & 4,67 & 4,01 & 3,50 & 3,09 \\
\hline 40 & 26,03 & 18,13 & 13,37 & 10,28 & 8,17 & 6,65 & 5,54 & 4,69 & 4,03 & 3,52 & 3,10 \\
\hline 41 & 26,18 & 18,24 & 13,45 & 10,34 & 8,21 & 6,69 & 5,57 & 4,71 & 4,05 & 3,53 & 3,11 \\
\hline 42 & 26,33 & 18,34 & 13,52 & 10,39 & 8,25 & 6,72 & 5,59 & 4,74 & 4,07 & 3,55 & 3,13 \\
\hline 43 & 26,48 & 18,44 & 13,59 & 10,45 & 8,30 & 6,76 & 5,62 & 4,76 & 4,09 & 3,56 & 3,14 \\
\hline 44 & 26,62 & 18,54 & 13,66 & 10,50 & 8,34 & 6,79 & 5,65 & 4,78 & 4,11 & 3,58 & 3,15 \\
\hline 45 & 26,76 & 18,63 & 13,73 & 10,56 & 8,38 & 6,82 & 5,67 & 4,80 & 4,12 & 3,59 & 3,16 \\
\hline 46 & 26,90 & 18,73 & 13,80 & 10,61 & 8,42 & 6,85 & 5,70 & 4,82 & 4,14 & 3,60 & 3,17 \\
\hline 47 & 27,03 & 18,82 & 13,87 & 10,66 & 8,46 & 6,88 & 5,72 & 4,84 & 4,16 & 3,62 & 3,18 \\
\hline 48 & 27,16 & 18,91 & 13,93 & 10,71 & 8,50 & 6,92 & 5,75 & 4,86 & 4,17 & 3,63 & 3,20 \\
\hline 49 & 27,29 & 19,00 & 14,00 & 10,76 & 8,53 & 6,95 & 5,77 & 4,88 & 4,19 & 3,65 & 3,21 \\
\hline 50 & 27,42 & 19,08 & 14,06 & 10,80 & 8,57 & 6,97 & 5,80 & 4,90 & 4,21 & 3,66 & 3,22 \\
\hline
\end{tabular}




\section{CONCLUSÃO}

O tamanho ótimo de parcela para avaliar a massa verde de aveia preta é de 4,14 unidades experimentais básicas de $1 \mathrm{~m}^{2}\left(4,14 \mathrm{~m}^{2}\right)$. Quatro repetições, para avaliar até 50 tratamentos, nos delineamentos inteiramente casualizado e blocos ao acaso, são suficientes para identificar, como significativas a $5 \%$ de probabilidade, pelo teste de Tukey, diferenças entre médias de tratamentos de $26,7 \%$ da média do experimento.

\section{AGRADECIMENTOS}

Ao Conselho Nacional de Desenvolvimento Científico e Tecnológico (CNPq) e à Coordenação de Aperfeiçoamento de Pessoal de Nível Superior (CAPES), pela concessão de bolsas aos autores. À Fundação de Amparo à Pesquisa do Estado do Rio Grande do Sul (FAPERGS), pela bolsa de iniciação científica e auxílio financeiro. Aos alunos bolsistas e voluntários, pelo auxílio na coleta de dados.

\section{REFERÊNCIAS}

CARGNELUTTI FILHO, A. et al. Tamanhos de parcela e de ensaio de uniformidade em nabo forrageiro. Ciência Rural, v.41, p.1517-1525, 2011. Disponível em: <http://www.scielo.br/pdf/cr/ v41n9/a9911cr5182.pdf>. Acesso em: 31 out. 2013. doi: 10.1590/ S0103-84782011005000119

CARVALHO, W.P. et al. Desempenho agronômico de plantas de cobertura usadas na proteção do solo no período de pousio. Pesquisa Agropecuária Brasileira, v.48, p.157-166, 2013. Disponível em: <http://www.scielo.br/pdf/pab/v48n2/48n02a05.pdf>. Acesso em: 31 out. 2013. doi: 10.1590/S0100-204X2013000200005.

CRUSCIOL, C.A.C. et al. Taxas de decomposição e de liberação de macronutrientes da palhada de aveia preta em plantio direto. Bragantia, v.67, p.481-489, 2008. Disponível em: <http://www. scielo.br/pdf/brag/v67n2/a24v67n2.pdf >. Acesso em: 31 out. 2013. doi: 10.1590/S0006-87052008000200024.

CRUZ, C.D. Programa genes: estatística experimental e matrizes. Viçosa: UFV, 2006. 285p.

DEBIASI, H. et al. Produtividade de grãos e componentes do rendimento da aveia preta (Avena strigosa Schreb) afetados pela densidade e velocidade de semeadura. Ciência Rural, v.37, p.649655, 2007. Disponível em: <http://www.scielo.br/pdf/cr/v37n3/ a08v37n3.pdf>. Acesso em: 30 out. 2013. doi: 10.1590/S010384782007000300008 .

HENRIQUES NETO, D. et al. Tamanho de parcela para avaliação da produção em trigo irrigado, sob dois sistemas de plantio. Revista Ciência Agronômica, v.40, p.86-93, 2009. Disponível em: <http://ccarevista.ufc.br/seer/index.php/ ccarevista/article/viewFile/408/304>. Acesso em: 01 nov. 2013
MARTINS, J.D. et al. Influência da densidade e velocidade de semeadura no crescimento da aveia preta (Avena strigosa Schreb.), em semeadura direta. Pesquisa Agropecuária Gaúcha, v.14, p.33-40, 2008. Disponível em: <http://www.fepagro.rs.gov.br/ upload/20120224145705vol14__n01__art05.pdf >. Acesso em: 31 out. 2013.

MAULI, M.M. et al. Variation on the amount of winter cover crops residues on weeds incidence and soil seed bank during an agricultural year. Brazilian Archives of Biology and Technology, v.54, p.683-690, 2011. Disponível em: <http://www.scielo.br/pdf/ babt/v54n4/06.pdf>. Acesso em: 30 out. 2013.

PARANAÍBA, P.F. et al. Tamanho ótimo de parcelas experimentais: proposição de métodos de estimação. Revista Brasileira de Biometria, v.27, p.255-268, 2009. Disponível em: <http://jaguar. fcav.unesp.br/RME/fasciculos/v27/v27_n2/Patricia.pdf >. Acesso em: 31 out. 2013 .

PIMENTEL-GOMES, F. Curso de estatística experimental. 13.ed. Piracicaba: Nobel, 1990. 468p.

R DEVELOPMENT CORE TEAM. R: a language and environment for statistical computing. Vienna: R Foundation for Statistical Computing, 2013. Disponível em: 〈http://www.R-project.org>. Acesso em: 31 out. 2013.

RAMALHO, M.A.P. et al. Experimentação em genética e melhoramento de plantas. Lavras: UFLA, 2005. 322p.

SALGADO, P. et al. Oats (Avena strigosa) as winter forage for dairy cows in Vietnam: an on-farm study. Tropical Animal Health and Production, v.45, p.561-568, 2013. Disponível em: <http:// link.springer.com/article/10.1007\%2Fs11250-012-0260-8>. Acesso em: 31 out. 2013. doi: 10.1007/s11250-012-0260-8.

SANTI, A. et al. Adubação nitrogenada na aveia preta. I - Influência na produção de matéria seca e ciclagem de nutrientes sob sistema plantio direto. Revista Brasileira de Ciência do Solo, v.27, p.1075-1083, 2003. Disponível em: <http://www.scielo.br/pdf/ rbcs/v27n6/19202.pdf>. Acesso em: 31 out. 2013. doi: 10.1590/ S0100-06832003000600012.

SOUZA, L.C.de. et al. Produção de matéria seca e matéria verde de aveia preta (Avena strigosa) em cinco idades de corte. In:ZOOTEC 2009, Águas de Lindóia, SP. Anais... Águas de Lindóia: Associação Brasileira de Zootecnistas, 2009. p.1-3. Disponível em: <http://www. abz.org.br/publicacoes-tecnicas/anais-zootec/artigos-cientificos/ forragicultura-pastagens/21420-Produo-matria-seca-matria-verdeaveia-preta-Avena-strigosa-cinco-idades-corte.html>. Acesso em: 31 out. 2013.

STORCK, L. et al. Experimentação vegetal. 3.ed. Santa Maria: UFSM, 2011. 200p.

TORRES, J.L.R. et al. Produção de fitomassa por plantas de cobertura e mineralização de seus resíduos em plantio direto. Pesquisa Agropecuária Brasileira, v.43, p.421-428, 2008. Disponível em: <http://www.scielo.br/pdf/pab/v43n3/ a18v43n3.pdf > . Acesso em: 31 out. 2013. doi: 10.1590/S0100204X2008000300018. 